\title{
Adaptation-related changes in the spatial and temporal summation of frog retinal ganglion cells
}

Donner, K.

Blackwell

1987

Acta Physiologica Scandinavica. 1987. 131: 479-487

http://hdl.handle.net/1975/946

Downloaded from Helda, University of Helsinki institutional repository.

This is an electronic reprint of the original article.

This reprint may differ from the original in pagination and typographic detail.

Please cite the original version. 


\title{
Adaptation-related changes in the spatial and temporal summation of frog retinal ganglion cells
}

\author{
K. DONNER \\ Department of Zoology, Division of Physiology, University of Helsinki, Finland
}

DONNER, K. 1987 . Adaptation-related changes in the spatial and temporal summation of frog retinal ganglion cells. Acta Physiol Scand r31, 479-487. Received 28 October I986, accepted I I June I987. ISSN ooo I-6772. Department of Zoology, Division of Physiology, University of Helsinki, Finland.

\begin{abstract}
The spatial and temporal summation of light by the receptive field centre of frog retinal ganglion cells were studied by extracellular recording in the eyecup preparation. The purpose was to quantify how summation changes with the state of light and dark adaptation and to clarify whether changes are due to the transition between rod and cone vision. Spatial summation was found to decrease by $30-50 \%$ as the cell was lightadapted to a threshold some $4 \log$ units above the dark-adapted one. Temporal summation for threshold responses fell as the power -0.17 of the intensity of an adapting steady background. Neither change was bound to the rod-cone transition but occurred in the ranges of both receptor types; at equal sensitivities the summation of both receptor systems was matched.
\end{abstract}

Key words: frog, ganglion cell, light-adaptation, receptive field, retina, visual summation.

By summing photon signals in space and time a ganglion cell both attains high sensitivity to light and manages to discern signals from background noise (see e.g. Barlow, 1956; Reuter et al. 1986). Its summation properties are characterized by a summation area (really the spatial sensitivity distribution of the receptive field (RF) centre) and a summation (or integration) time. The extent and duration of a stimulus may or may not exceed the summation area and time respectively, so obviously the ganglion cell cannot uniquely respond to intensity. Considering the situation only spatially, this means that ' $f l u x$, not retinal illumination, is what retinal ganglion cells really care about' (Enroth-Cugell \& Shapley I973). Including the time domain, it means that photon dosis is the relevant quantity. Neither summation area nor time need be constant, however: from a functional point of view both should be wide at low light levels, to favour sensitivity, while at

Correspondence: Kristian Donner, Department of Zoology, Division of Physiology, University of Helsinki, Arkadiankatu 7, SF-оoıоo Helsinki, Finland high light levels they might be expected to contract to favour spatio-temporal resolution.

A moderate reduction of the summation area with light adaptation has been suggested by several authors (Glezer I965, Enroth-Cugell \& Robson I966, Bäckström \& Reuter 1975; Donner I98I a, Derrington \& Lennie I982), but as pointed out by Shapley \& Enroth-Cugell (I984), it is not known how the contraction depends on adaptation level, nor whether it depends on the receptor type (rod or cone) active. Adaptational changes in summation time have never been thoroughly explored at the level of the retinal ganglion cell, although that would provide a base for comparison with psychophysical results, making it possible to infer the retinal contribution to changes observed in the visual system as a whole (e.g. Barlow 1958).

The aim of the present work was to get a quantitative picture of how light-adaptation changes the spatial and temporal summation of the excitatory receptive field centre of frog retinal ganglion cells. It is shown that there is (I) a gradual moderate decrease in summation area, (2) a substantial decrease in summation time at 
threshold, which largely parallels, but is not explicable by changes at the photoreceptor level.

\section{MATERIALS AND METHODS}

Response thresholds and full impulse discharges of retinal ganglion cells were extracellularly recorded from the isolated eyecup of the common frog (Rana temporaria L.). The frogs had been caught in October in southern Finland and stored at $4{ }^{\circ} \mathrm{C}$ without feeding. Before dissection the frog was kept overnight in a dark chamber where the temperature was allowed to rise gradually to some $\mathrm{I} 5{ }^{\circ} \mathrm{C}$. The eye was excised, the anterior part removed and the vitreous drained to a depth of $0 . \mathrm{I}-0.3 \mathrm{~mm}$ on a cooled surface under dim red light. The eyecup was then transferred to the recording chamber and allowed to adapt in complete darkness for at least $\mathrm{I} h$ before the experiment started. The spiking threshold of the dark-adapted ganglion cells in this preparation was often very low (some $5^{-10}$ photoisomerizations within the receptive field, see e.g. Donner 1987), which gives reason to think that the eyecups were in a physiologically healthy condition. Temperature was kept at $10-12{ }^{\circ} \mathrm{C}$, which is a normal temperature for active frogs in the Finnish summer.

During most experiments the eye was either fully dark-adapted or kept at some steady adaptation level with a full-field background light. In some experiments the eye was given a short light exposure bleaching $3 \%$ of the rhodopsin and the process of dark-adaptation monitored. The light source was a high-pressure xenon arc (Osram XBO, $900 \mathrm{~W})$ delivering light into two channels: one for stimulation and one for background illumination. The absolute light intensities (quanta $\mathrm{mm}^{-2} \mathrm{~s}^{-1}$ ) incident on the retina through each channel were measured with an Airam UVM-8 radiometer especially calibrated over the whole visible spectrum. The main features of the dissection, recording and stimulation techniques have been described elsewhere (Donner \& Reuter ı968, Bäckström et al. 1978) and the reader is referred to these publications for a fuller account. For the translation of incident light intensities into rates of photo-isomerizations in frog rods, see Reuter et al. (1986).

The stimuli used throughout this work were circular spots of light (diameters $0.027,0.05 \mathrm{I}, 0.1 \mathrm{I}, 0.18,0.30$, 0.53 and $0.80 \mathrm{~mm}$ on the retina) delivered as square steps $(>5$ s) or flashes (durations $2,4,8,17,33,67$, I25, 250, 500 or $1000 \mathrm{~ms}$ ) with a Compur electronic shutter. All results refer to on-type responses of class I, 2 or 3 ganglion cells (see e.g. Bäckström \& Reuter 1975, Donner \& Grönholm 1984).

Most of the results are based on determinations of the ganglion cell spiking threshold in various stimulus situations. Threshold was taken as the lowest intensity of the stimulus eliciting at least one spike on about half of the trials. (Observe that frog ganglion cells show a very low spontaneous activity, usually less than I spike per $2 \mathrm{~min}$.) Intensity was repeatedly decreased and increased in o.r log unit steps until the threshold intensity was known with reasonable accuracy. In practice, the determination of one threshold value usually required 10-20 trials. With a few identifiable exceptions (conditions with low signal-to-noise ratio, cf. Donner 1987 ), the accuracy thus attained in stable steady-state conditions corresponds to a log threshold standard deviation of less than 0.1 log units.

In one series of experiments (e.g. that presented in Fig. 3) the latencies of supra-threshold responses to various stimuli were taken as measures of the relative strength of the responses. Latency was measured from stimulus onset to the midpoint of the first spike and always determined as the mean of three or more presentations of the same stimulus. In these experiments the impulse discharges were stored as trains of dots on a Tektronix $5_{103} \mathrm{~N}$ storage oscilloscope triggered by the onset of the stimulus and latencies were measured from Polaroid photographs of the oscilloscope screen.

Measures of summation. It was convenient to use compact measures of summation; therefore the actual more complicated weighting distributions describing the extent of summation in space and time were replaced by 'top-hat' and square-wave models respectively, giving sharp boundaries to summation - a radius in space, a sharp limit in time. These widely used linear models assume that all photons falling within the boundaries are linearly summed with equal weight (cf. the psychophysical laws of Riccò and Bloch), while the effect of any photon falling outside them is nil, and that the integrated sensitivity is equal to that of the real distribution. Expressed somewhat differently, the models define the summation area as the ratio of the threshold flux of photons $\left(\mathrm{q} \mathrm{s}^{-1}\right.$ measured with a small stimulus) to threshold intensity $\left(\mathrm{q} \mathrm{mm} \mathrm{m}^{-2} \mathrm{~s}^{-1}\right.$ with a large stimulus, see equation (I) below), and the summation time as the ratio of the threshold density of photons delivered $\left(\mathrm{q} \mathrm{mm}^{-2}\right.$ measured with a brief flash) to the threshold intensity ( $\mathrm{q} \mathrm{mm} \mathrm{mm}^{-2} \mathrm{~s}^{-1}$ with a step stimulus; see equation (2) below). The summation area $A_{\mathrm{s}}$ is then given by

$A_{\mathrm{s}}=\left(I_{0} / I_{\mathrm{L}}\right) A_{0}$,

where $A_{0}$ and $I_{0}$ are the area and threshold intensity of a stimulus much smaller than $A_{\mathrm{s}}$ and $I_{\mathrm{L}}$ is the threshold intensity of a stimulus much larger than $A_{\mathrm{s}}$. For more detailed considerations of the rationale, see e.g. Barlow (1953), Cleland \& Enroth-Cugell (I968), Bäckström \& Reuter (I975) and Donner \& Grönholm (1984). Note that the equation can be applied not only in connection with threshold, but in connection with any response measure having a monotone dependence on photon signals linearly summed (e.g. latency; see the Results section). 


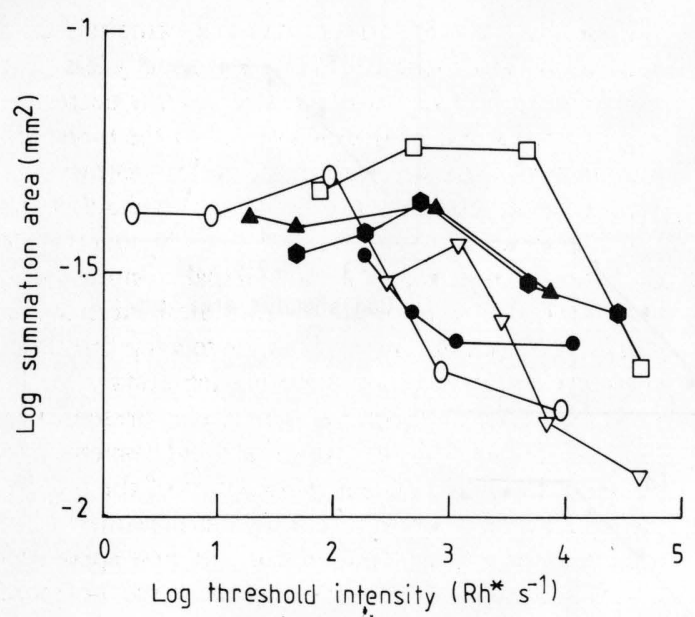

Fig. I. The size of the central summation area of the $\mathrm{RF}$ as a function of the state of adaptation for six cells. Each type of symbols refers to recordings from one cell. Abscissa : log number of photoisomerizations per second within the summatory receptive field centre necessary for evoking a threshold response at the time a size was determined. This number expresses the degree of light-adaptation. Ordinates: $\log$ area $\left(\mathrm{mm}^{2}\right)$ of the centre. Sizes were determined according to equation (I) with $5^{\mathrm{I}} 3 \mathrm{~nm}$ step stimuli. (The 'small' stimulus in equation (I) was a spot of $0.1 \mathrm{Imm}$ diameter, the 'large' stimulus had 0.53 or $0.80 \mathrm{~mm}$ diameter, always exceeding the size of the centre.) All recordings were made during the rod branch of darkadaptation after an exposure bleaching $3 \%$ of the rhodopsin of an initially dark-adapted eye.

The summation or integration time $t_{\mathrm{i}}$ is given by $t_{\mathrm{i}}=\left(I_{\mathrm{f}} / \mathrm{I}_{1}\right) t_{\mathrm{f}}$

where $t_{\mathrm{f}}$ and $I_{\mathrm{f}}$ are the duration and threshold intensity of a flash much shorter than $t_{\mathrm{i}}$ and $I_{\mathrm{i}}$ is the threshold intensity of a (spatially coextensive) stimulus much longer than $t_{\mathrm{i}}$. This $t_{\mathrm{i}}$ is equivalent to the integration time of Baylor \& Hodgkin (1973).

Statistics. The results are given as mean \pm SEM. Significance levels were obtained by Student's $t$, or, for area-threshold recordings, by the $z$ statistic, assuming $\sigma=0$.I $\log$ units for a single threshold determination (see above).

\section{RESULTS}

\section{Spatial summation}

Summation decreases with light-adaptation both in the rod and in the cone range. Fig. I plots the size of the receptive field's summatory centre when driven by the red rods as a function of the state of adaptation. Centre sizes have been determined according to equation ( $\mathrm{I}$ ) in six cells at various moments during the rod phase of dark-adaptation after a bleach. It is seen that as light-adaptation pushes threshold intensity above some 100 isomerizations $\mathrm{s}^{-1}$ within the centre (each rod is then hit approximately every fifth second) its size starts decreasing more or less monotonically with rising threshold intensity. In this sample of cells the mean area of the RF centres decreases $(P<0.005)$ from darkadapted $0.038 \mathrm{~mm}^{2}$ to the most light-adapted $0.020 \mathrm{~mm}^{2}$. That implies a decrease in spatial summation by nearly $50 \%$ over a $4 \log$ unit range of threshold adaptation.

Fig. 2 shows full area-threshold functions recorded from one cell at three adaptation levels; dark-adapted, mesopic and photopic. The use of a primarily rod-depressing $(5 \mathrm{I} 3 \mathrm{~nm})$ background for adaptation made it possible to select a mesopic level where thresholds to blue light $(495 \mathrm{~nm})$ were determined by rods and thresholds to red light $\left(6{ }_{5} 5 \mathrm{~nm}\right)$ by cones (see Fig. 2a). The size of the mesopic summatory centre as determined with these two wavelengths differed little, if at all - at equal sensitivities the rod- and the cone-determined summation areas nearly match (Fig. 2 c, d). However, going to an adaptation level $2 \log$ units higher, the size of the now cone-driven centre has decreased $(P<0.02)$ by about $40 \%$ (Fig. $2 \mathrm{e}$ vs. c).

The contraction is not due to lateral inhibition. In the following experiments the adaptationconnected decrease in summation area was measured also by means of the inhibitioninsensitive parameter response latency in order to rule out the possibility that the changes are due to effectivized lateral inhibition. The ratio $I_{0} / I_{\mathrm{L}}$ in equation ( $\mathrm{I}$ ) is then determined at a constantlatency criterion instead of a threshold criterion. To improve the statistics, the ratio can be determined at many different criterion levels, in fact for the whole (stimulus intensity)-(response latency) function (see Donner I98I b, Donner \& Grönholm I984). It is then most practical to plot reciprocal latency against log stimulus intensity, because this function is a straight line.

The results of one such experiment are shown in Fig. 3, where the open symbols show the dark-adapted and the filled symbols show the light-adapted latency functions recorded with a small (triangles) and a large spot (circles). In the dark-adapted case, the function obtained with 


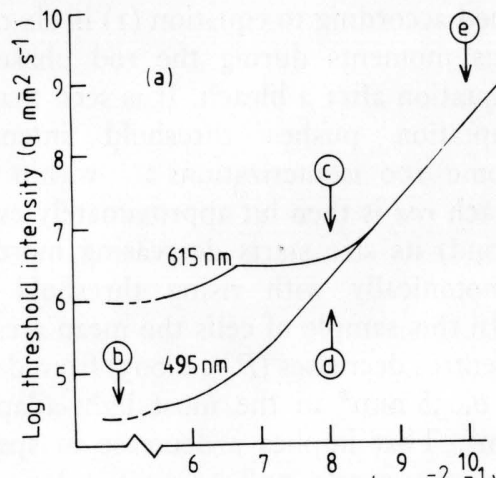

Log background intensity (q $\mathrm{mm}^{-2} \mathrm{~s}^{-1}$ )

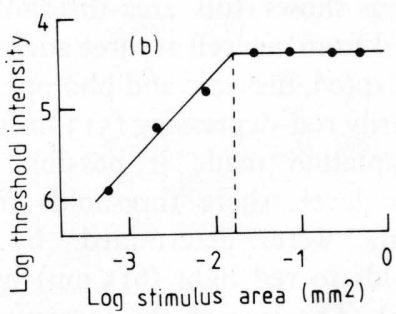

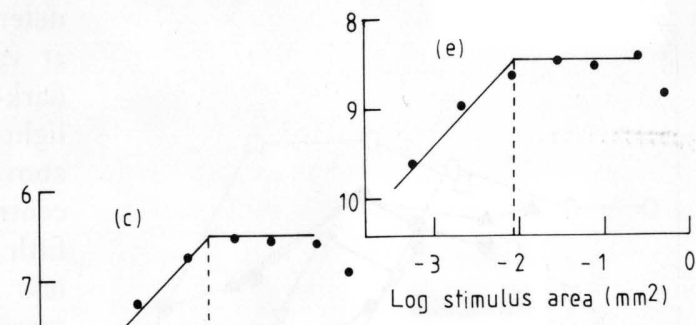
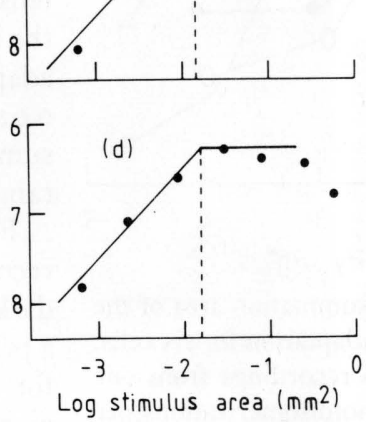

Log stimulus area $\left(\mathrm{mm}^{2}\right)$

Fig. 2. Spatial summation of rod and cone signals in different states of adaptation. (b)-(e) Areathreshold curves recorded from the same cell against $513 \mathrm{~nm}$ backgrounds of different intensities as shown in (a). The stimulus wavelengths (495 and 615 nm) were chosen to separate rod- and cone-mediated thresholds. (a) The states of adaptation in which each of the curves (b)-(e) was recorded, indicated on the increment-threshold functions of the cell as recorded with a rodfavouring $(495 \mathrm{~nm})$ and a cone-favouring $\left(61_{5} \mathrm{~nm}\right)$ 0.1 $8 \mathrm{~mm}$ stimulus spot against a primarily roddepressing $(5 \mathrm{I} 3 \mathrm{~nm})$ background of increasing intensity (data points have been suppressed for clarity of presentation). This procedure makes it possible to distinguish cone-driven $\left(6 \mathrm{I}_{5} \mathrm{~nm}\right)$ thresholds from rod-driven $(495 \mathrm{~nm})$ ones. (b) Dark-adapted thresholds : $495 \mathrm{~nm}$ stimuli, roddriven responses. (c, d) Thresholds adapted by a weak background : (c) -6 I $5 \mathrm{~nm}$ stimuli, conedriven responses, (d) $-495 \mathrm{~nm}$ stimuli, rod-driven responses. (e) Thresholds adapted by a stronger background: $615 \mathrm{~nm}$ stimuli, cone-driven responses. Abscissae in (b)-(e): log area $\left(\mathrm{mm}^{2}\right)$ of the stimulating spot. Ordinates: $\log$ threshold intensity (quanta $\mathrm{mm}^{-2} \mathrm{~s}^{-1}$, step stimuli). The size of the summation area is indicated by the point of intersection between the horizontal and the sloping $\left(45^{\circ}\right)$ segments, as shown by the vertical dashed lines.

the small spot is seen to replicate that obtained with the large spot at I.4 log unit higher intensities throughout. In the light-adapted case the distance between the lines is 0.9 log units. It follows that the summation area has decreased $(P<0.00 \mathrm{I})$ from $0.05 \mathrm{I}$ to $0.016 \mathrm{~mm}^{2}$. This is even slightly (though not significantly) more than the decrease suggested by conventional area-threshold recording in the same cell, from 0.046 to $0.023 \mathrm{~mm}^{2}$. The conclusion is that the decrease indicated by area-threshold recording cannot be accounted for by effectivized lateral inhibition.

Summation areas were determined by use of both thresholds and latencies in a sample of four cells, first in the dark-adapted state, then against a background elevating thresholds by about 3.5 log units. The results were completely consistent: in all four cells both methods showed a decrease with light-adaptation. The mean decrease was $47 \%$ as judged by thresholds, $33 \%$ as judged by latencies.

\section{Temporal summation at threshold}

Figure 4 shows a full flash duration - threshold intensity function from a dark-adapted cell, illustrating the logic of equation (2) for de- 


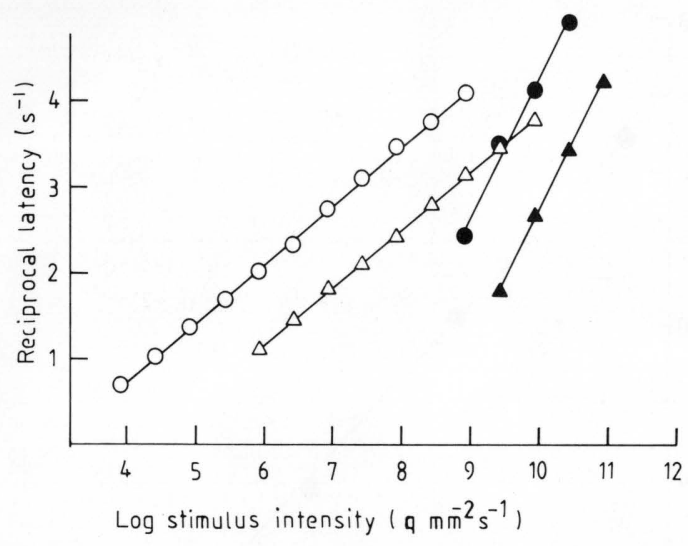

Fig. 3. The change in summation area with light adaptation in one ganglion cell as judged by response latencies. The horizontal distance between the parallel lines of a pair is a relative measure of the extent of summation in the dark-adapted state (open symbols) and the light-adapted state (filled symbols). The plot shows reciprocal response latencies of the ganglion cell as functions of $\log$ stimulus intensity. Responses to a small (0.05 $\mathrm{Imm}$ diameter: triangles) and a large ( $0.8 \mathrm{~mm}$ diameter; circles) $5^{\mathrm{I}} 3 \mathrm{~nm}$ spot were recorded in the dark-adapted state (open symbols) and against a strong $615 \mathrm{~nm}$ background giving about $\mathrm{I} .5 \times 1 \mathrm{I}^{10}$ incident quanta $\mathrm{mm}^{-2} \mathrm{~s}^{-1}$ (filled symbols). Latencies were determined as the mean of at least three consecutive recordings. Lines were fitted by linear regression and the horizontal $\log$ intensity distance between the lines of each pair was determined at the mean point of the large-spot lines. The antilog of this distance is the factor by which the summation area exceeds the area of the small spot (see text).

termining summation time $t_{\mathrm{i}}$. In a $\log$-log plot the points fall on a $45^{\circ}$ line expressing complete summation of photons up to a limit from where increased duration no longer lowers threshold intensity. That limit, $t_{i}$, is about $2 \mathrm{~s}$ in Fig. 4. The mean value obtained from a sample of I9 dark-adapted cells at I I $^{\circ} \mathrm{C}$ was $t_{\mathrm{i}}=$ 2. $\mathrm{I} \pm 0.2 \mathrm{~s}$.

Figure 5 shows how threshold summation time in one cell shortened as the retina was exposed to steady adapting background lights. In Fig. $5 \mathrm{a}$ the data are plotted against the logarithm of the prevailing threshold intensity (expressing the degree of light-adaptation, cf. Fig. I). It is seen that light-adaptation elevating the spiking threshold by 4 log units brought down summation to only $0.2 \mathrm{~s}$ or about $7 \%$ of its

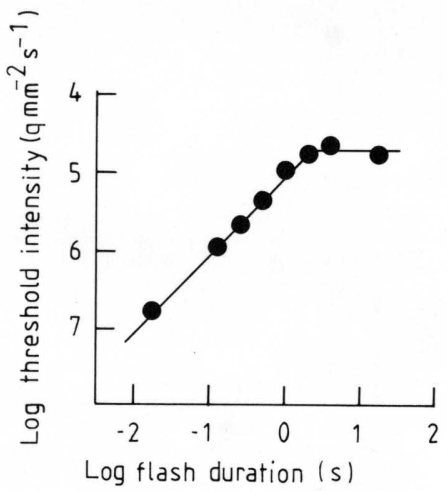

Fig. 4. How threshold intensity falls with increasing stimulus duration. In this $\log -\log$ plot the $45^{\circ}$ line fitted to the points for short flash durations represents complete reciprocity between intensity and duration ('complete temporal summation' or what is psychophysically known as Bloch's law). The horizontal line indicates a range where stimulus duration has no effect on threshold. The point of intersection of these two lines shows the limit of temporal summation, the summation time $t_{\mathrm{i}}$. $-5^{\mathrm{I}} 3 \mathrm{~nm}$ stimulus of $0.18 \mathrm{~mm}$ diameter.

dark-adapted value. In Fig 5 b the results have been replotted as a $\log -\log$ plot against background intensity. When the data are presented in this way, a straight-line relationship obtains, implying that $t_{\mathrm{i}}$ and $I$ are related by a power function. The slope of the line $(-0.2$ in the figure) is the exponent, for which experiments on seven cells gave a mean value $-0.17 \pm 0.03$. So if $I_{\mathrm{B}}$ is the intensity of the background,

$t_{\mathrm{i}} \propto I_{\mathrm{B}}{ }^{-0.17}$.

In Fig. 5 at least the two most dark-adapted summation times are purely rod-determined and at least the most light-adapted one purely cone-determined: the decrease in temporal summation is not restricted to either receptor system or to the rod-cone transition. For clarity, it is worth referring back to the cell of Fig. 2, where the receptor contributions are clearly distinguished in the various states of adaptation. There, the respective summation times at threshold were: $2.64 \mathrm{~s}$ (Fig. $2 \mathrm{~b}$, dark-adapted rod threshold), 0.66 and $0.59 \mathrm{~s}$ (Fig. $2 \mathrm{~d}$, c, moderately light-adapted rod and cone thresholds, respectively) and $0.17 \mathrm{~s}$ (Fig. 2e, lightadapted cone threshold). [ $t_{\mathrm{i}}$ in (c) and (d) are not significantly different $(P>0.4)$, but smaller 

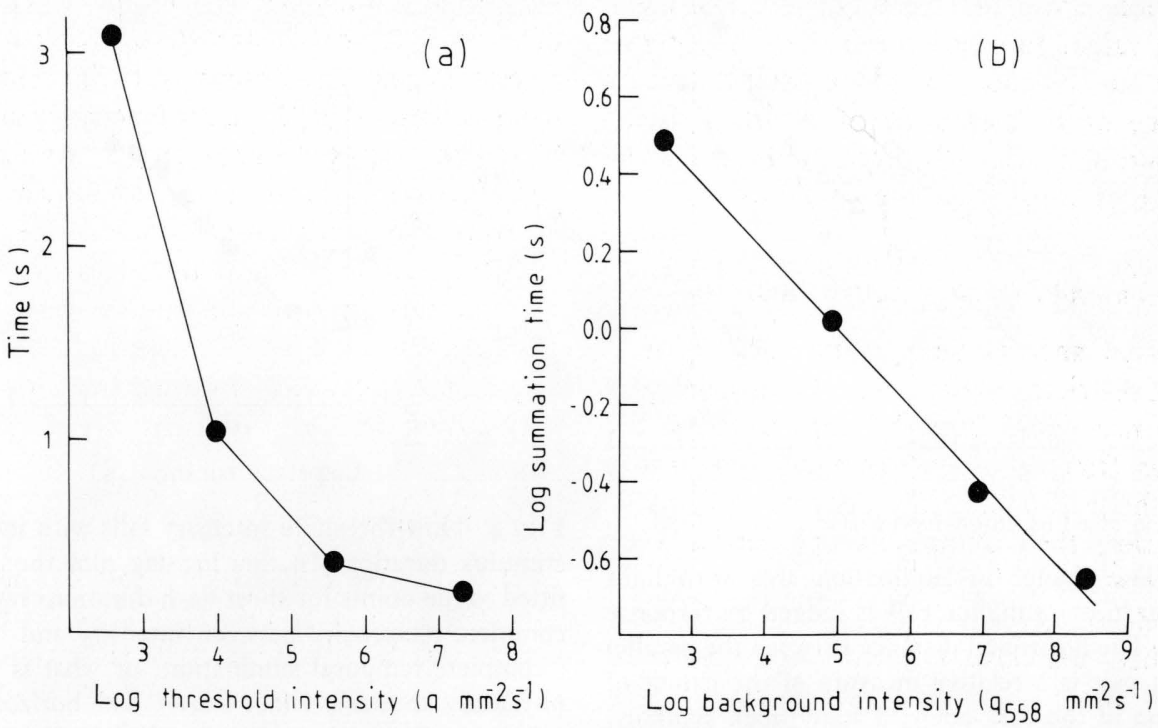

Fig. 5. The shortening of threshold summation time $t_{\mathrm{i}}$ with increasing intensities of adapting background illumination. (a) As a function of the cell's threshold, which is used to indicate the degree of light-adaptation. (b) The same data as in (a) re-plotted (on logarithmic ordinates) against $\log$ background intensity $I_{\mathrm{B}}$. As $\log t_{\mathrm{i}} v s . \log I_{\mathrm{B}}$ yields a straight line, $t_{\mathrm{i}}$ is a power function of $I_{\mathrm{B}}$. The 'dark' background (for the leftmost point in (b), where no real background is present) has been calculated from the rate of spontaneous isomerization-like events in anuran rods. In the common frog at II. $5{ }^{\circ} \mathrm{C}$ this rate is 0.006 events per rod and second, or the equivalent of about 540 quanta $_{558} \mathrm{~mm}^{-2} \mathrm{~s}^{-1}$ incident on the retina (see Baylor et al. 1980 ; Reuter et al. 1986). The cell was initially dark-adapted, but the backgrounds were not presented in intensity order. Backgrounds were $55^{8} \mathrm{~nm}$ and stimuli $5 \mathrm{I} 3 \mathrm{~nm}$.

than in (b) at $P<0.00 \mathrm{I} ; t_{\mathrm{i}}$ in (e) is smaller than in (c) and (d) at $P<0.0 \mathrm{I}$.]

\section{The total effect of light-adaptation on summation at threshold}

For the validity of the conclusions it was necessary to ascertain that the summation times did not depend on the size of the stimulus, nor the summation areas on the duration of the stimulus. Either way, it would show up if full area-threshold curves are measured first with a step, then with a brief flash stimulus. No trace of an interaction was observed; one and the same intensity shift always brought the flash thresholds to all spots to coincide with the corresponding step thresholds (for spot sizes not extending far into the inhibitory RF surround).

If the fall-off of total summation is expressed as a general power law like relation (3), the exponent relating summation to background intensity becomes $-0.2 \mathrm{r}$. This value is obtained as follows. A 4 log unit rise in threshold reduces spatial summation by some $40 \%$ (see above), thereby multiplying $A_{\mathrm{s}}$ by the factor o.6. The background intensity necessary for accomplishing such a threshold rise corresponded to $2700 \pm 1400$ photoisomerizations per rod and second $(n=4)$; i.e. $5.7 \log$ units more than the 'dark light' 0.006 isomerizations/(rod s) (see legend to Fig. 5). Thus the exponent -0.I7 describing the decrease in temporal summation (relation (3)) is augmented by $(\lg 0.6) / 5.7=$ -0.04 due to the decrease in spatial summation.

\section{DISCUSSION}

The present work shows that the spatio-temporal summation of a ganglion cell is adjusted by light already prior to the further modulation by an IRF-type inhibitory signal (Grüsser \& GrüsserCornehls I973). A moderately strong background light, raising thresholds by $3 \cdot 5^{-4} \log$ units, reduces spatial summation by about $40 \%$ and temporal summation by over $90 \%$, bringing total 
summation down to some $5 \%$ of its darkadapted value. In other words, over this range changes in summation alone will cause a difference of at least a factor of 20 in lightadaptation as revealed by thresholds to a longand-large $v s$. a brief-and-small stimulus.

\section{Summation and the rod/cone transition}

The spatial and temporal summation changes were not restricted to the range of either receptor system, nor could they be explained by the transition from one to the other. In conditions where the rod and cone systems had equal sensitivities, their summation properties were closely matched. A similar smooth transition from rod- to cone-driven response kinetics is seen when response latencies are considered (Donner 1984). This explains how a 'silent substitution' of different-wavelength stimuli can sometimes be possible even when both rods and cones are active (Donner \& Rushton 1959). On the other hand the very smallest (most lightadapted) summation areas and shortest summation times cannot be attained by the rod system, just as the cone system can never reach the very extensive spatio-temporal summation of the fully dark-adapted rod system.

\section{Spatial summation}

A decrease in spatial summation accompanied light-adaptation, whether by steady background lights or by the bleaching of a fraction of the pigment in the receptors. This decrease must be based on true neural adaptation in the postreceptoral network. Quantitatively, the rather modest reduction of the central summation area agrees well with values reported from cat ganglion cells. Derrington \& Lennie (I982) found a $32 \%$ reduction as background was raised by 5 log units; Enroth-Cugell \& Robson ( 1966 ) report a $50 \%$ reduction over about $4.5 \mathrm{log}$ units of background intensity. (As explained above, the adaptation of threshold by $3 \cdot 5^{-4} \log$ units used here corresponds to a background intensity range of roughly $5 \mathrm{log}$ units.) In the frog, Donner (I98I a) has compared mean darkadapted, rod-determined and mean lightadapted, cone-determined summation areas, finding that the latter were $c a .50 \%$ smaller.

In one sense the contraction of the summation area is obviously useful: in a linear cell it is the size of the summatory receptive field centre that determines the spatial high-frequency cut-off (cf. Enroth-Cugell \& Robson 1984). The improvement in spatial resolution, however, would at a first glance appear rather slight. Possibly, the main functional significance of the contraction is to shift the centre-surround balance in the receptive field in favour of the surround. A slight shift in this balance can greatly amplify the effects of the surround (Donner I 98 r a, b, I985), resulting in effectivized attenuation of low spatial frequencies.

\section{Temporal summation}

In the temporal domain a decreased summation time for increment responses was seen as the retina was light-adapted. This agrees qualitatively with the improved resolution observed already by Granit \& Riddell (I934) in recordings of the critical flicker frequency (CFF) in frog ERG. Yet one should not facetiously attribute all aspects of this change to light-adaptation. The improved capacity for following flicker which accompanies the transition to light-adapted states has to be connected with both a faster rise and a faster decay of the responses to light. Only the decay phase is truly accelerated by lightadaptation (for responses from frog rods, see Hemilä 1977), whereas the steep rise appears as a trivial consequence of the use of high stimulus intensities in light-adapted states. In fact, the onset of the response to a flash of light of fixed intensity is fastest in a dark-adapted eye. Lightadaptation actually extends the early kinetical parameters: for a fixed flash intensity, both ganglion cell latencies and the time interval within which photons can effect the early part of the response (the 'critical duration' for affecting latency and initial discharge rate) get longer the stronger the adapting background (Donner I984, I985).

\section{Adaptational changes in psychophysical summation}

Barlow (1958) describes psychophysical experiments on human spatio-temporal summation, which are in some respects comparable to the present ones. Above all, there is a clear similarity in the overall dependence of threshold summation on background intensity : Barlow's results indicate that summation falls as the power 
-0.25 of background intensity; in the present work the dependence of total summation on background intensity could be described with the power $-0.2 \mathrm{I}$. Thus there is no compelling reason to postulate a central origin for that decrease in visual summation. Arguably, such a simple power law could predominantly reflect retinal adaptation, whereas additional psychophysical effects (interaction between area and duration, extensive partial summation) clearly reflect central processes.

A similar basic agreement is found when temporal summation is considered in isolation. Keller (194I) recorded the 'critical durations' of threshold intensity increments (i.e. summation times such as here illustrated by Fig. 4), concluding that the durations changed with adaptation according to a negative power function of the adapting intensity. In her experiments the best-fitting exponent was -0.12 , which is reasonably close to the mean value -0.17 obtained here.

\section{Photoreceptor and ganglion cell summation times compared}

Dark-adapted rods. To what extent does temporal summation in ganglion cells simply replicate the properties of the photoreceptors at the retinal input? There is little explicit data on summation times in anuran photoreceptors. In dark-adapted rods in the eye-cup of Bufo marinus, $t_{\mathrm{i}}$ for responses in the linear range has been found to average $\mathrm{I} .9 \mathrm{~s}$ at $20^{\circ} \mathrm{C}$ (D.R. Copenhagen, K. Donner \& T. Reuter, in preparation). Assuming a $Q_{10}$ of 2.2 (Lamb I984) that corresponds to $3.9 \mathrm{~s}$ at I I $^{\circ} \mathrm{C}$.

By the use of a suitable model, summation times can be calculated from the times to peak $t_{\mathrm{p}}$ of small (linear range) responses. If the 'independent activation' model of Baylor et al. (1974) is used with $n$ (the number of steps) $=4$, it can be shown that $t_{\mathrm{i}}=\mathrm{I} .7 t_{\mathrm{p}}$ (Donner I985). By this method a $t_{\mathrm{i}}=6 \mathrm{~s}$ has been calculated from preliminary intracellular recordings from the species studied here (K. Donner \& S. Hemilä, unpublished), while Lamb's (I984) recordings (Bufo) would suggest $3 \cdot 4-6.8 \mathrm{~s}$. The dispersion is uncomfortably wide, but there is a clear indication that rod summation times are slightly longer than the ganglion cell value $2.1 \mathrm{~s}$ found here. This is consistent with the notion that the transmission chain contains differ- entiating elements (Baylor \& Fettiplace 1977; Schnapf \& Copenhagen I982; Copenhagen $e t$ al. I983; Marchiafava \& Torre 1978 ).

Changes with adaptation. Hemilä (1977) recorded the light-adaptation of the frog's aspartate-isolated rod receptor potential both with step and brief flash stimulation, applying a constant-amplitude criterion. Summation times extracted from his published data by use of equation (2) indicate a decrease with the power -0.10 of background intensity, i.e. somewhat less than the value -0.17 obtained here for ganglion cells.

Intermediate between these two are Hood's \& Grover's (1974) results on the frog's aspartateisolated cone potential. These authors studied the decrease in temporal summation both with rising background and with rising stimulus intensities. They publish only two dark-adapted and two light-adapted recordings (their fig. 2), but if a power law is assumed, their data would indicate an exponent of -0.14 for 'threshold' summation as function of background intensity.

At any rate, ganglion cell summation times can clearly adapt independently of photoreceptor summation times. For example, in Fig. $5, t_{i}$ is halved by a background light giving each rod an isomerization only every fifth second on average. In the eyecup of Bufo marinus at $20^{\circ} \mathrm{C}$, a background producing 0.9 isomerizations per rod and second (i.e. nearly five times stronger) has been found to reduce rod $t_{\mathrm{i}}$ by only $22 \%$ (D.R. Copenhagen, K. Donner \& T. Reuter, in preparation). A calculation according to relation (3) of the present work suggests that for a $22 \%$ reduction of frog ganglion cell summation times in the same conditions, a background of 0.08 isomerizations per rod and second would suffice (the dark light for frog rods at $20^{\circ} \mathrm{C}$ has then been taken as 0.019 isomerizations per rod and second; c.f. Baylor et al. (I980) and Reuter et al. (1986))

I wish to thank Drs Tom Reuter and Simo Hemilä for critically reading earlier versions of the manuscript.

\section{REFERENCES}

Bä́ckström, A.-C., Hemilä, S. \& Reuter, T. 1978. Directional selectivity and colour coding in the frog retina. Med Biol 56, 72-83.

BÄCKSTRÖM, A.-C. \& ReUTER, T. 1975. Receptive field organization of ganglion cells in the frog retina: 
contributions from cones, green rods and red rods. 7 Physiol (Lond) 246, 79-107.

BARLOW, H.B. I953. Summation and inhibition in the frog's retina. 7 Physiol (Lond) I 19, 69-88.

BARLOW, H.B. I956. Retinal noise and absolute threshold. 7 Opt Soc Am 46, 634-639.

BARLOw, H.B. 1958. Temporal and spatial summation in human vision at different background intensities. 7 Physiol (Lond) r4I, 337-350.

Baylor, D.A. \& Fettiplace, R. I977. Kinetics of synaptic transfer from receptors to ganglion cells in turtle retina. 7 Physiol (Lond) 271, 425-448.

BAYLOR, D.A. \& Hodgkin, A.L. I973. Detection and resolution of visual stimuli by turtle photoreceptors. 7 Physiol (Lond) 234, 163-198.

BAYLOR, D.A., HodgKin, A.L. \& LAMB, T.D. 1974. The electrical response of turtle cones to flashes and steps of light. 7 Physiol (Lond) 242, 685-727.

Baylor, D.A., Matthews, G. \& Yau, K.-W. I980. Two components of electrical dark noise in toad retinal rod outer segments. 7 Physiol (Lond) 309, $59 \mathrm{I}-62 \mathrm{I}$.

Cleland, B.G. \& Enroth-Cugell, C. i968. Quantitative aspects of sensitivity and summation in the cat retina. 7 Physiol (Lond) 198, I7-38.

Copenhagen, D.R., Ashmore, J.F. \& Schnapf, J.K. 1983. Kinetics of synaptic transmission from photoreceptors to horizontal and bipolar cells in turtle retina. Vision Res 23, 363-369.

Derrington, A.M. \& LenNie, P. I982. The influence of temporal frequency and adaptation level on receptive field organization of retinal ganglion cells in cat. 7 Physiol (Lond) 333, 343-366.

DONNER, K. I98I a. Receptive fields of frog retinal ganglion cells: response formation and light-darkadaptation. 7 Physiol (Lond) 319, I3I-I42.

DONNER, K. I $98 \mathrm{I}$ b. How the latencies of excitation and inhibition determine ganglion cell thresholds and response patterns in the frog. Vision Res $2 \mathbf{I}$, I689-I692.

DONNER, K. I984. Rod and cone driven response latencies of frog retinal ganglion cells. Proc Int Soc Eye Res 3, 26.

DONNER, K. 1985. The ganglion cells of the frog retina: receptive field mechanisms and adaptational changes in these. Ph.D. thesis, University of Helsinki.

DONNER, K. 1987. The absolute sensitivity of vision: can a frog become a perfect detector of lightinduced and dark rod events? Physica Scripta (in press.)

DONNER, K. \& Grönholm, M.-L. I984. Center and surround excitation in the receptive fields of frog retinal ganglion cells. Vision Res 24, 1807-1819.
DONNER, K.O. \& Reuter, T. ig68. Visual adaptation of the rhodopsin rods in the frog's retina. 7 Physiol (Lond) 199, 59-87.

Donner, K.O. \& Rushton, W.A.H. I959. Retinal stimulation by light substitution. 7 Physiol 149, 288-302.

Enroth-Cugell, C. \& Robson, J.G. i966. The contrast sensitivity of retinal ganglion cells of the cat. 7 Physiol (Lond) 187, 517-552.

Enroth-Cugell, C. \& Robson, J.G. I984. Functional characteristics and diversity of cat retinal ganglion cells. Basic characteristics and functional description. Invest Ophthal 25, 250-267.

Enroth-Cugell, C. \& Shapley, R.M. i973. Flux, not retinal illumination is what cat retinal ganglion cells really care about. 7 Physiol (Lond) 233, 3I I -326 .

GLEZER, V.D. I 965 . The receptive fields of the retina. Vision Res 5, 497-525.

Granit, R. \& Riddell, H.A. I934. The electrical responses of light- and dark-adapted frog's eyes to rhythmic and continuous stimuli. 7 Physiol (Lond) 8I, I-28.

GRÜSSER, O.-J. \& GRÜSSER-CORNEHLS, U. I973. Neuronal mechanisms of visual movement perception and some psychophysical and behavioral correlations. In: R. Jung (ed.) Handbook of Sensory Physiology. Vol. VII/3A. Central Processing of Visual Information, part A, Springer, Berlin.

HemiLÄ, S.O. I977. Background adaptation in the rods of the frog's retina. 7 Physiol (Lond) 265, $72 \mathrm{I}-74 \mathrm{I}$.

Hood, D.C. \& Grover, B.G. I974. Temporal summation of light by a vertebrate visual receptor. Science 184, 1003-1005.

KeLleR, M. I94I. The relation between the critical duration and intensity in brightness discrimination. 7 exp Psychol 28, 407-4I8.

LAMB, T.D. 1984. Effects of temperature changes on toad rod photocurrents. 7 Physiol (Lond) 346, 557-578.

MarchiafaVa, P.L. \& Torre, V. 1978. The responses of amacrine cells to light and intracellularly applied currents. 7 Physiol (Lond) 276, 83-102.

Reuter, T., Donner, K. \& Copenhagen, D.R. 1986. Does the random distribution of discrete photoreceptor events limit the sensitivity of the retina? Neurosci Res suppl. 4, Si63-Si8o.

SChnapf, J.K. \& Copenhagen, D.R. I982. Differences in the kinetics of rod and cone synaptic transmission. Nature 296, 862-864.

Shapley, R.M. \& ENroth-Cugell, C. I984. Visual adaptation and retinal gain controls. In : N. Osborne \& G. Chader (eds) Progress in Retinal Research, vol. 3. Pergamon, Oxford. 